\title{
Clinical value of Xenopus kinesin-like protein 2 as a prognostic marker in patients with digestive system cancers: a systematic review and meta-analysis
}

This article was published in the following Dove Press journal:

OncoTargets and Therapy

\author{
Gang Wangl,* \\ Qian Wangl,* \\ Zhengyan $\mathrm{Li}^{2}$,* \\ Chaoxu Liu ${ }^{3}$ \\ Xianli $\mathrm{He}^{\prime}$
}

'Department of General Surgery, Tangdu Hospital, Fourth Military Medical University, Xi'an, China; ${ }^{2}$ Department of Surgery, Xijing Hospital of Digestive Diseases, Fourth Military Medical University, Xi'an, China; ${ }^{3}$ Department of General Surgery, Huashan Hospital, Fudan University, Shanghai, China

*These authors contributed equally to this work
Correspondence: Xianli He

Department of General Surgery,

Tangdu Hospital, Fourth Military Medical

University, 169 West Changle Street,

Xi'an, 7 10038 , China

Tel +8621 66895079

Fax +862164085875

Email xianlihe66@I63.com

\begin{abstract}
Xenopus kinesin-like protein 2 (TPX2) is a microtubule-associated protein that plays an important role in spindle assembly and dynamics. However, the clinical and prognostic value of TPX2 in the digestive system cancers remains unclear. The objective of this review was to evaluate the association of TPX2 expression with disease-free survival (DFS), overall survival (OS), and clinicopathological features of digestive system cancers. The software Stata 12.0 was used to analyze the outcomes, including OS, disease-free survival (DFS), and clinicopathological characteristics. A total of 10 eligible studies with 906 patients were included. Elevated TPX2 expression was significantly associated with poor DFS (pooled hazard ratio $[\mathrm{HR}]=2.48,95 \%$ confidence interval [CI]: 1.96-3.13) and OS (pooled HR =2.66, 95\% CI: 2.04-3.48) of digestive system malignancies. Subgroup analyses showed that cancer type, sample size, study quality, and laboratory detection methods did not alter the significant prognostic value of TPX2. Additionally, TPX2 expression was found to be an independent predictive factor for DFS (HR $=2.31$, 95\% CI: 1.78-3.01). TPX2 expression might be associated with TNM stage and pathological grade in digestive system cancer. In conclusion, TPX2 is an independent prognostic factor for survival of patients with digestive system cancer. Furthermore, its overexpression is associated with TNM stage and pathological grade in digestive system cancer.
\end{abstract}

Keywords: digestive system neoplasm, TPX2, meta-analysis, prognosis

\section{Introduction}

Digestive system cancers, one of the most common malignancies, have overtaken cardiovascular disease and infectious diseases as a major cause of morbidity and mortality in the world. ${ }^{1-3}$ They cause approximately 2.9 million deaths per year. ${ }^{4}$ Although novel targeted therapies for terminal cancer patients are emerging, the application range is still limited. ${ }^{5}$ Therefore, it is of great importance to identify applicable prognostic biomarkers to improve the unfavorable prognosis.

Xenopus kinesin-like protein 2 (TPX2), a $100 \mathrm{kDa}$ protein, was first described by Heidebrecht et al in $1997 .{ }^{6}$ Human TPX2, a microtubule-associated protein located in chromosome $20 \mathrm{q} 11.2,{ }^{7,8}$ was reported to play an important role in spindle assembly and dynamics. ${ }^{9,10}$ In addition, TPX2 was found to participate in the regulation of cell mitosis or meiosis. ${ }^{11,12}$ Overexpression of TPX2 could cause DNA aneuploidy and polyploidy. ${ }^{13,14}$ The aberrant expression of TPX2 could inhibit normal mitosis and lead to carcinogenesis. Thus, TPX2 expression might have great potential for a more precise evaluation of progression of malignancy.

Among numerous independent studies, the clinical predictive value of TPX2 in patients with cancer, especially digestive system cancer, remains controversial. 
A recently published work by Liu et al revealed a significant relationship of positive TPX2 to cancer stage III/IV and cancer grade of differentiation. ${ }^{15}$ Huang et al also showed that TPX2 level was positively associated with (TNM) tumor stage and Edmondson-Steiner grading. ${ }^{16}$ In obvious contrast, TPX2 expression was not correlated with TNM stage, cancer grade of differentiation, and tumor capsule according to the study by Liang et al. ${ }^{17}$ No correlation between TPX2 expression and tumor staging, grading, or TNM stage was indicated. ${ }^{18}$

The conflicting results lead to an unresolved issue on the relationship of TPX2 expression with clinical outcomes of cancer patients. Therefore, we performed the meta-analysis to evaluate the association of TPX2 expression with disease-free survival (DFS), overall survival (OS), and clinicopathological features of digestive system cancers.

\section{Methods}

\section{Literature search strategy}

The meta-analysis was conducted according to the Preferred Reporting Items for Systematic Reviews and Meta-Analyses (PRISMA) statement and guidelines. ${ }^{19}$ Details of the preferred reporting items for systematic reviews and metaanalyses statement criteria used are available in Table S1. A comprehensive literature search from electronic databases PubMed, EMBASE, Cochrane library, CBM, and Chinese CNKI was performed (up to July 2016). Search keywords were ("TPX2" or "Xklp2" or "Xenopus kinesin-like protein 2 ") and ("tumor" or "malignancy" or "neoplasia" or "cancer" or "carcinoma") and "prognosis" or "survival" or "outcome" or "mortality". Reference lists in the included studies were also searched manually to identify potential studies.

\section{Selection criteria}

\section{Inclusion criteria}

(1) Cohort studies and case-control studies.

(2) Studies investigating any type of digestive system cancers.

(3) Studies providing data for the estimation of the hazard ratio (HR) for OS or DFS with $95 \%$ confidence intervals (CIs) included.

(4) Studies where the association between TPX2 and clinical prognosis was clarified.

(5) Studies of TPX2 overexpression based on primary cancer tissues.

(6) The most samples and most informative studies when the duplicate studies were published.

\section{Exclusion criteria}

(1) Studies irrelevant to digestive system cancers.
(2) Studies which assessed patients with metastatic cancers other than primary cancer.

(3) Data that were incomplete or could not be combined.

(4) Case reports, comments, letters, meeting abstract, systematic reviews, and meta-analysis.

\section{Data extraction}

Data extraction tables were set up to enter data from each study, including first author, publication year, country of origin, type of tumor, TNM stage, number of patients recruited, cut-off value, TPX2 expression and detection method, preoperative treatment, outcome measures, follow-up time, survival analysis, and HRs with the corresponding 95\% CIs (Table 1). Two authors (QW and GW) independently assessed the quality of the studies, and a consensus decision was made regarding any discrepancies by a third investigator (XLH).

Under the condition that the total number of events and the corresponding $p$-values were not reported in text, several survival rates at specified times from Kaplan-Meier survival curves were extracted using the Engauge Digitizer version 4.1. The extracted survival rates at specified times were input into the calculation spreadsheet developed by Tierney et $\mathrm{al}^{20}$ to reconstruct the survival curve and produce the HRs with their 95\% CIs.

\section{Quality assessment}

Study quality in this meta-analysis was assessed using the Quality Scale for Biological Prognostic Factors reported previously. ${ }^{21} \mathrm{QW}$ and GW independently assessed the quality of each study according to the quality scale (Table S2). ${ }^{21}$ The quality scale was focused on four aspects: scientific design, laboratory methodology, generalizability, and result analysis. The overall maximum points were 40 . The global scores were presented as percentages, ranging from $0 \%$ to $100 \%$. Studies with higher proportion values were considered high quality. Any discrepancies on the eligibility of studies were resolved by a third reviewer (XLH) until the two original reviewers reached consensus.

\section{Statistical analysis}

Statistical analysis was performed by STATA version 12.1 (StataCorp LP, College Station, TX, USA). Heterogeneity was detected using the $I^{2}$ statistic $(25 \%, 50 \%$, and $75 \%$ indicated low, moderate, and high heterogeneity, respectively). In this analysis, $I^{2}<50 \%$ indicated low heterogeneity, and $I^{2}>50 \%$ indicated substantial heterogeneity. Both fixed- and randomeffect models were assessed for the pooled estimates. 


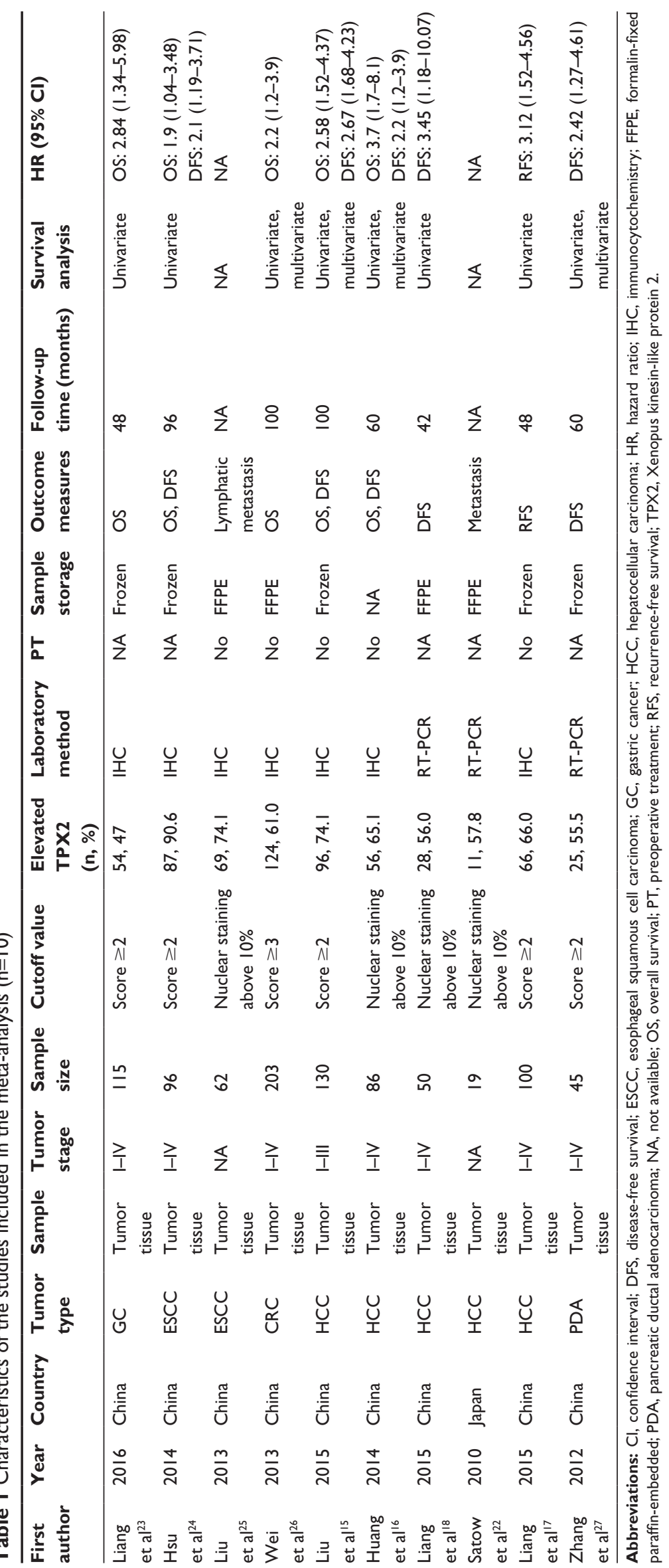


Furthermore, cumulative meta-analysis was performed to show the trend in the estimated effect. Subgroup analyses were carried out on cancer type, sample size, quality score, and laboratory detection method. Sensitivity analysis was carried out by sequentially omitting individual study to guarantee the stability of the results. The odds ratios (ORs) with corresponding 95\% CIs were used to assess the correlation between TPX2 expression and clinicopathological features. Egger's regression plot and Begg's test were used to evaluate the risk of publication bias.

\section{Results}

\section{Study characteristics}

The search strategy retrieved 174 potentially relevant studies. According to the inclusive criteria, 10 eligible studies with a total of 906 patients, conducted in two countries (nine in China and one in Japan), were included in this metaanalysis. ${ }^{15-18,22-27}$ The flowchart of study selection is shown in Figure 1. Study characteristics of these studies are summarized in Table 1. Among the studies included, five focused on hepatocellular carcinoma (HCC), and two were about esophageal squamous cell carcinoma (ESCC), with single studies about gastric cancer, pancreatic cancer, and colon cancer. There were seven studies for DFS, five for OS, and one for recurrence-free survival (RFS). Expression of TPX2 was evaluated by immunocytochemistry (IHC) in seven studies, and reverse transcription polymerase chain reaction (RT-PCR) was adopted in the remaining three studies. The total positive rate of TPX 2 was $63.7 \%$ (from $47 \%$ to $90.6 \%$ ). The maximum and minimum sample sizes were 203 and 19, respectively. The quality assessment of the included studies is shown in Table 2.
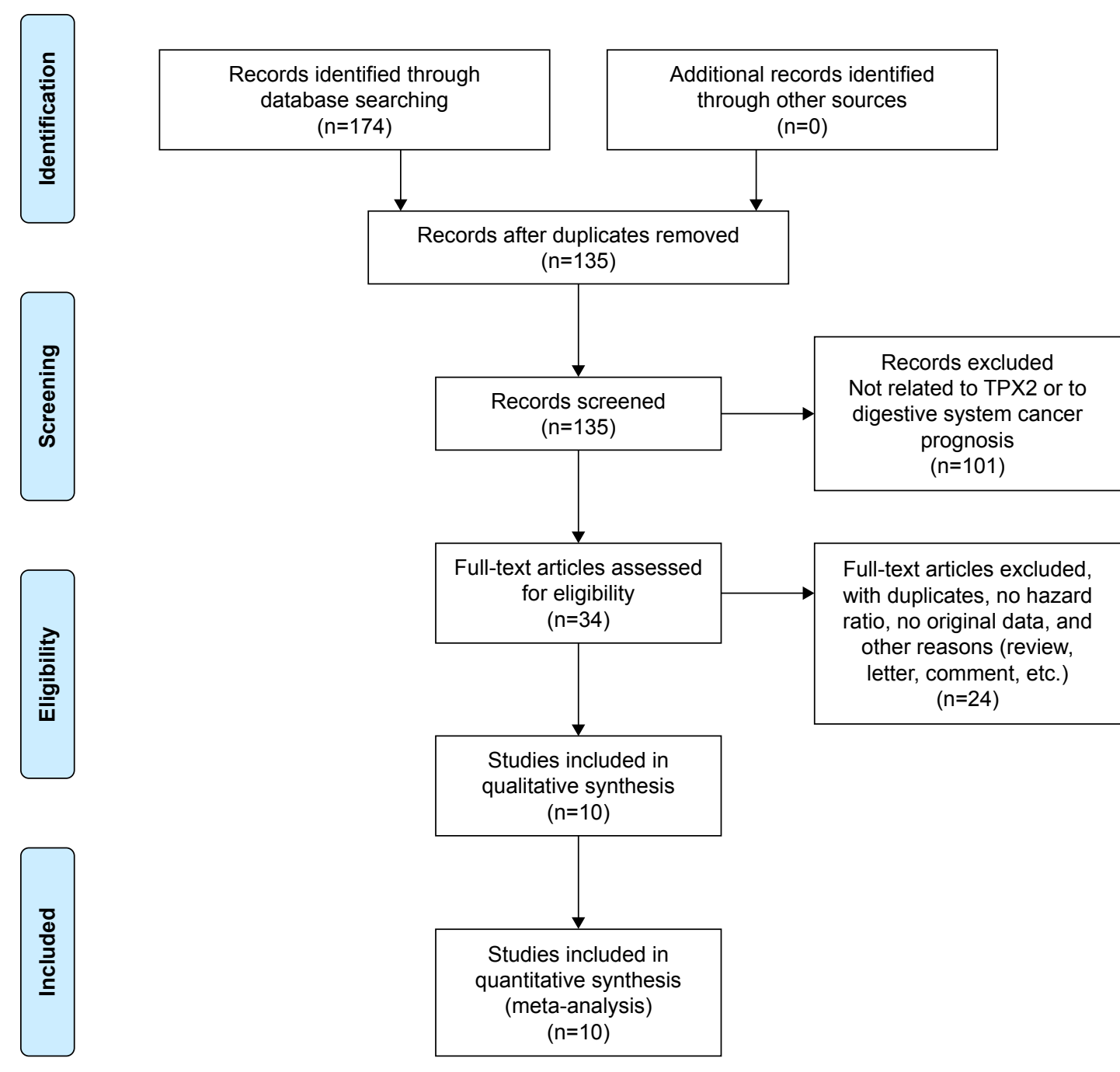

Figure I Flowchart of the process of identifying relevant studies. Abbreviation: TPX2, Xenopus kinesin-like protein 2. 
Table 2 Quality assessment of the included studies based on the quality scale for biological prognostic factors

\begin{tabular}{|c|c|c|c|c|c|}
\hline Study & $\begin{array}{l}\text { Scientific } \\
\text { design }\end{array}$ & $\begin{array}{l}\text { Laboratory } \\
\text { methodology }\end{array}$ & Generalizability & $\begin{array}{l}\text { Results } \\
\text { analysis }\end{array}$ & $\begin{array}{l}\text { Global score } \\
\text { (\%) }\end{array}$ \\
\hline Liu et al $(2015)^{15}$ & 9 & 11 & 10 & 7 & 93 \\
\hline Huang et al $(2014)^{16}$ & 8 & 8 & 10 & 6 & 80 \\
\hline Liang et al $(2015)^{18}$ & 8 & 11 & 10 & 7 & 90 \\
\hline Satow et al $(2010)^{22}$ & 8 & 10 & 9 & 2 & 73 \\
\hline Liang et al (2015) ${ }^{17}$ & 9 & 11 & 10 & 4 & 85 \\
\hline Liang et al $(2016)^{23}$ & 9 & 10 & 9 & 6 & 85 \\
\hline Hsu et al $(2014)^{24}$ & 8 & 10 & 10 & 4 & 80 \\
\hline Liu et al $(2013)^{25}$ & 8 & 9 & 8 & 2 & 68 \\
\hline Wei et al $(2013)^{26}$ & 9 & 10 & 9 & 4 & 80 \\
\hline Zhang et al $(2012)^{27}$ & 8 & 9 & 8 & 4 & 73 \\
\hline
\end{tabular}

\section{Aberrant overexpression of TPX2 in digestive system cancers}

Meta-analysis using a random-effects model indicated that TPX2 was highly expressed in digestive system cancers, including liver cancer (pooled HR $=6.29,95 \% \mathrm{CI}: 4.50-8.81$ ), esophageal cancer (pooled HR $=6.35,95 \% \mathrm{CI}: 1.48-27.3$ ), gastric cancer (pooled HR $=3.74,95 \% \mathrm{CI}: 2.07-6.76$ ), and colon cancer $($ pooled HR $=78.09,95 \%$ CI: 27.90-218.56) (Figure 2).

\section{Prognostic value of TPX2 for DFS of digestive system cancers}

Among the studies included, a total of seven with 725 subjects reported HRs for DFS. As shown in Figure 3, it was indicated that elevated TPX2 expression predicted a poor outcome for DFS of digestive system cancer patients (pooled HR $=2.48$, 95\% CI: 1.96-3.13). In addition, a cumulative meta-analysis according to the time of publication was carried out. A stable trend of significant correlation between TPX2 overexpression

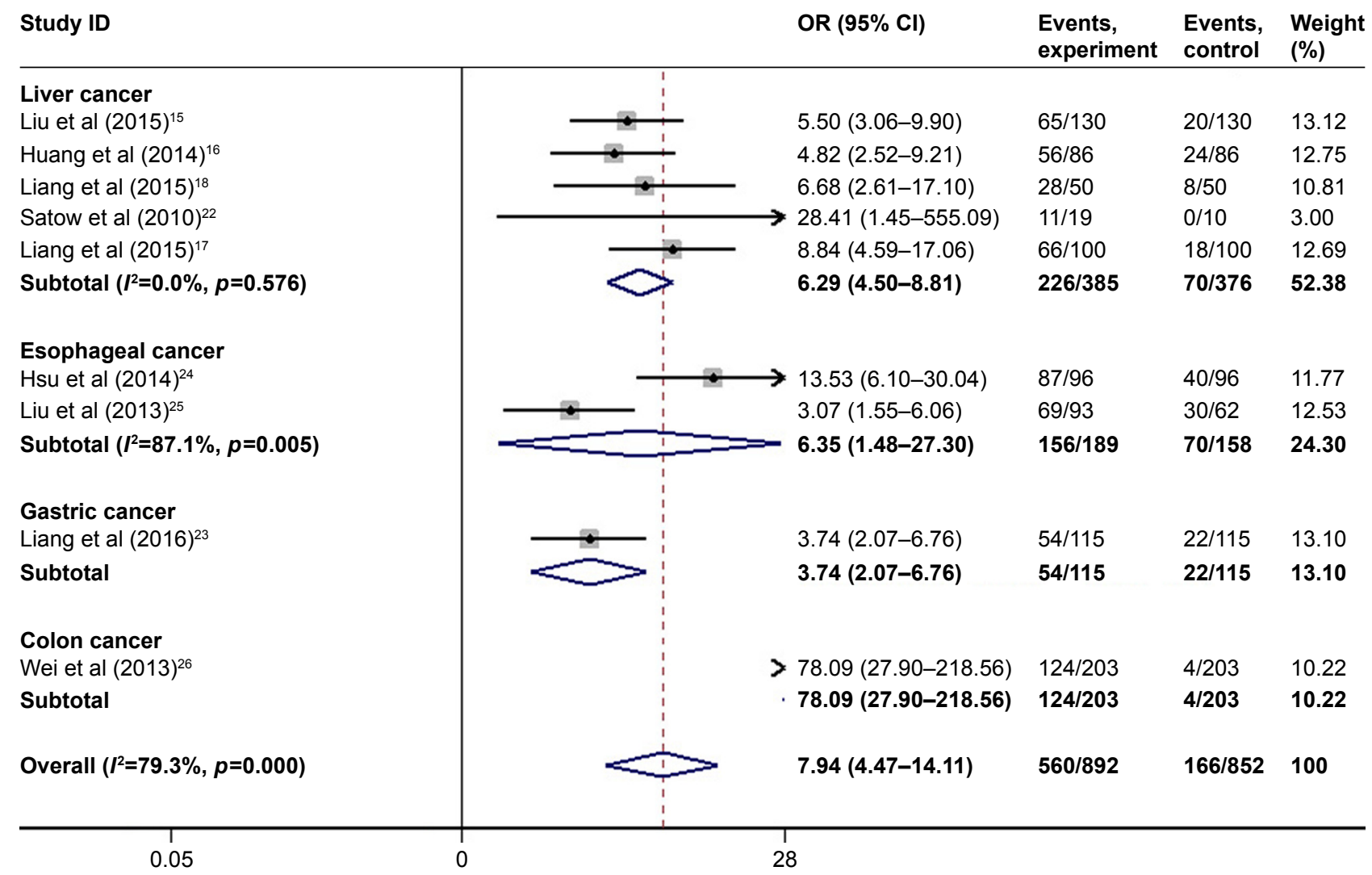

Figure 2 Meta-analysis of aberrant overexpression of TPX2 in digestive system cancers.

Note: Weights are from random-effects analysis.

Abbreviations: TPX2, Xenopus kinesin-like protein 2; OR, odds ratios; $\mathrm{Cl}$, confidence interval. 


\begin{tabular}{|c|c|c|}
\hline Study ID & $\mathrm{HR}(95 \% \mathrm{Cl})$ & Weight (\%) \\
\hline DFS & & \\
\hline Liu et al $(2015)^{15}$ & $2.67(1.68-4.24)$ & 14.40 \\
\hline Huang et al $(2014)^{16}$ & $2.20(1.20-4.03)$ & 8.36 \\
\hline Hsu et al $(2014)^{24}$ & $2.10(1.19-3.71)$ & 9.53 \\
\hline Liang et al $(2016)^{23}$ & $2.17(1.23-3.83)$ & 9.53 \\
\hline Wei et al $(2013)^{26}$ & $3.70(1.70-8.05)$ & 5.08 \\
\hline Zhang et al $(2012)^{27}$ & $2.42(1.27-4.61)$ & 7.39 \\
\hline Liang et al $(2015)^{17}$ & $3.45(1.18-10.09)$ & 2.67 \\
\hline Subtotal $\left(I^{2}=0.0 \%, p=0.903\right)$ & $2.48(1.96-3.13)$ & 56.97 \\
\hline os & & \\
\hline Liu et al $(2015)^{15}$ & $2.58(1.52-4.38)$ & 10.98 \\
\hline Huang et al $(2014)^{16}$ & $3.70(1.70-8.05)$ & 5.08 \\
\hline Hsu et al $(2014)^{24}$ & $1.90(1.04-3.48)$ & 8.39 \\
\hline Liang et al $(2016)^{23}$ & $3.60(2.08-6.23)$ & 10.21 \\
\hline Wei et al $(2013)^{26}$ & $2.20(1.20-4.03)$ & 8.36 \\
\hline Subtotal $\left(I^{2}=0.0 \%, p=0.488\right)$ & $2.66(2.04-3.48)$ & 43.03 \\
\hline
\end{tabular}

Figure 3 Meta-analysis of the pooled HRs of patients with elevated TPX2 expression. Note: Weights are from random-effects analysis.

Abbreviations: TPX2, Xenopus kinesin-like protein 2; HR, hazard ratio; Cl, confidence interval; DFS, disease-free survival; OS, overall survival.

and a poor DFS was confirmed as time accumulates with an increasingly narrow 95\% CI (Figure S1). Although no interstudy heterogeneity was observed in the quantitative synthesis ( $\left.I^{2}=0.0 \%, p=0.903\right)$, subsequent analyses of subgroups were performed on the basis of cancer type (liver, esophageal, gastric, colon, and pancreatic), sample size ( $\geq 100$ vs $<100$ ), quality score $(\geq 85 \%$ vs $<85 \%$ ), and laboratory detection method (RT-PCR vs IHC) (Figure 4). A significant correlation between TPX2 overexpression and a poor DFS was shown in patients with liver cancer $(\mathrm{HR}=2.57,95 \%$ $\mathrm{CI}$ : 1.82-3.64), esophageal cancer $(\mathrm{HR}=2.10,95 \% \mathrm{CI}$ : 1.19-3.71), gastric cancer ( $\mathrm{HR}=2.17,95 \% \mathrm{CI}: 1.23-3.83)$, colon cancer $(\mathrm{HR}=3.70,95 \% \mathrm{CI}: 1.70-8.05)$, and pancreatic cancer $(\mathrm{HR}=2.42,95 \% \mathrm{CI}: 1.27-4.61)$, indicating the expression level of TPX 2 could be used to predict the DFS of various kinds of digestive system malignancies. In the analysis stratified by the size of the sample, TPX2 was found to be significantly associated with DFS of patients in studies with sample size $>100(\mathrm{HR}=2.64,95 \% \mathrm{CI}: 1.91-3.66)$ and sample size $<100$ (HR $=2.32,95 \% \mathrm{CI}: 1.66-3.23)$. There was a significant association of increased TPX2 expression with DFS of patients in studies with a quality score of $>85 \%$
$(\mathrm{HR}=2.54,95 \% \mathrm{CI}: 1.81-3.57)$ and $<85 \%(\mathrm{HR}=2.42,95 \%$ CI: 1.76-3.33). Stratified analysis on the laboratory detection method revealed a significant relationship of elevated TPX2 to DFS of patients in both RT-PCR subgroup (HR $=2.66$, 95\% CI: $1.53-4.62$ ) and IHC subgroup (HR $=2.44,95 \%$ CI: 1.89-3.15). In order to evaluate the robustness of the pooled results, we conducted sensitivity analysis by sequentially omitting one study. The leave-one-out sensitivity analysis implied that no individual study altered the pooled estimates significantly (Figure 5A), validating the stability of our results.

\section{Prognostic value of TPX2 for OS and RFS of digestive system cancers}

Five studies comprising 630 individuals reported OS according to the expression level of TPX2, and one study consisting of 100 patients reported HRs and corresponding 95\% CIs for RFS. As shown in Figure 3, upregulated TPX2 expression was tightly associated with poor clinical outcome for OS (pooled HR =2.66, 95\% CI: 2.04-3.48) of digestive system tumors. We also conducted sensitivity analysis by sequentially omitting one study. The results showed that no 


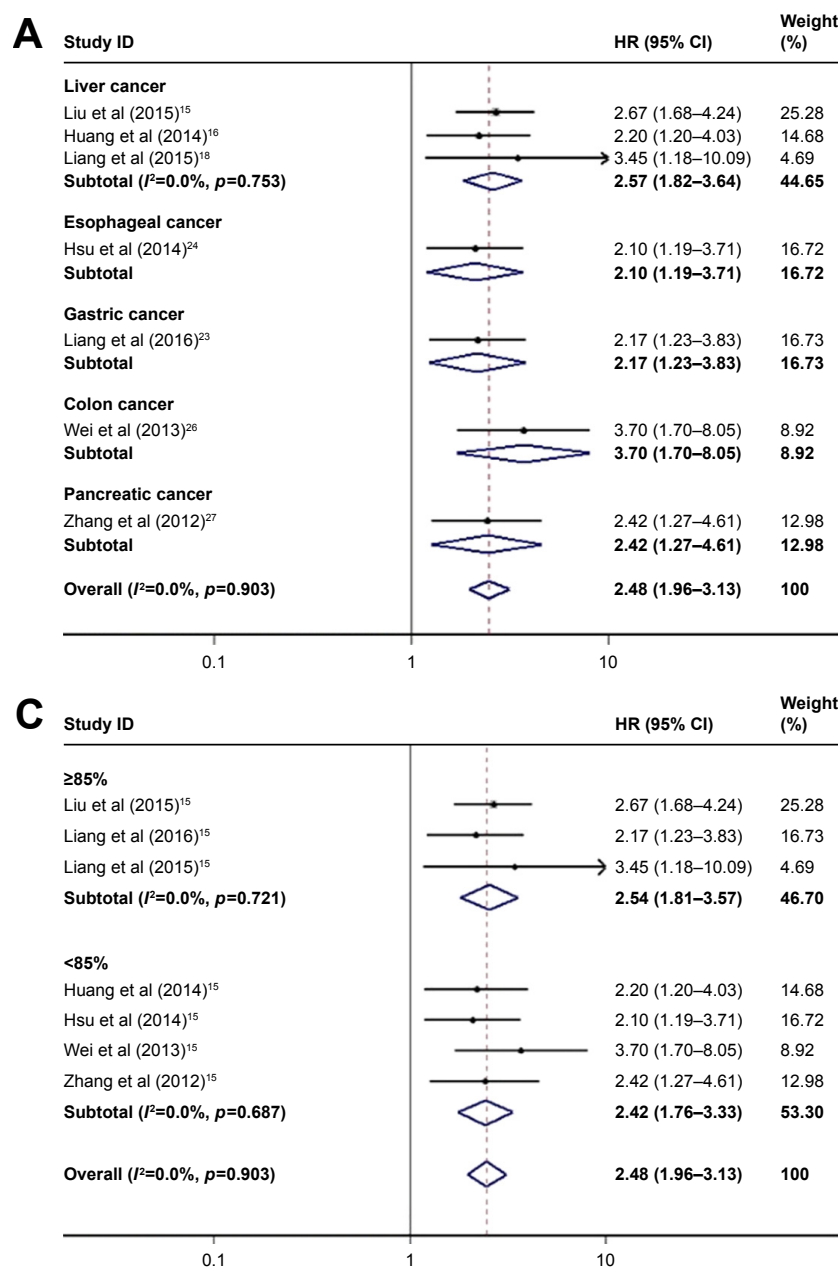

B

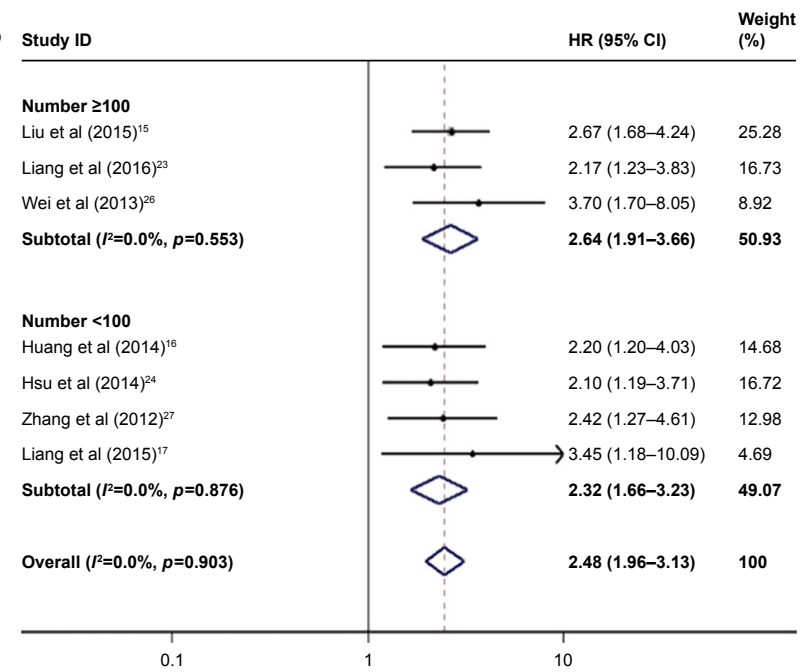

D

\begin{tabular}{|c|c|c|c|}
\hline Study ID & & HR $(95 \% \mathrm{Cl})$ & $\begin{array}{l}\text { Weight } \\
(\%)\end{array}$ \\
\hline \multicolumn{4}{|l|}{ RT-PCR } \\
\hline Zhang et al $(2012)^{27}$ & & $2.42(1.27-4.61)$ & 12.98 \\
\hline Liang et al $(2015)^{17}$ & & $3.45(1.18-10.09)$ & 4.69 \\
\hline Subtotal $(R=0.0 \%, p=0.579)$ & & $2.66(1.53-4.62)$ & 17.66 \\
\hline \multicolumn{4}{|l|}{$\mathrm{IHC}$} \\
\hline Liu et al $(2015)^{15}$ & & $2.67(1.68-4.24)$ & 25.28 \\
\hline Huang et al $(2014)^{16}$ & & $2.20(1.20-4.03)$ & 14.68 \\
\hline Hsu et al $(2014)^{24}$ & $\rightarrow$ & $2.10(1.19-3.71)$ & 16.72 \\
\hline Liang et al (2016) 23 $^{3}$ & $\longrightarrow$ & $2.17(1.23-3.83)$ & 16.73 \\
\hline Wei et al $(2013)^{26}$ & & $3.70(1.70-8.05)$ & 8.92 \\
\hline Subtotal $\left(I^{2}=0.0 \%, p=0.774\right)$ & $\diamond$ & $2.44(1.89-3.15)$ & 82.34 \\
\hline Overall $(l=0.0 \%, p=0.903)$ & $\diamond$ & $2.48(1.96-3.13)$ & 100 \\
\hline 01 & & & \\
\hline
\end{tabular}

Figure 4 Subgroup analyses were performed by the factors of cancer type (A), sample size (B), quality score (C), and laboratory detection method (D). Note: Weights are from random-effects analysis.

Abbreviations: $\mathrm{HR}$, hazard ratio; $\mathrm{Cl}$, confidence interval.

individual study altered the pooled estimates significantly (Figure 5B), validating the stability of our results. In addition, a cumulative meta-analysis according to the time of publication was carried out. A stable trend of significant correlation between TPX2 overexpression and a poor OS was confirmed as time accumulates with an increasingly narrow 95\% CI (Figure S2). Similarly, TPX2 overexpression was associated with a poor RFS (HR $=3.12,95 \%$ CI: $1.52-4.56$ ) in patients with $\mathrm{HCC}$.

\section{Independent prognostic value of TPX2 in digestive system cancers}

Cox multivariate analyses were performed in five studies, and the role of TPX2 as an independent predictive factor for OS of patients with digestive system cancer was investigated. The pooled results showed that TPX2 expression was an independent prognostic factor for OS of patients with digestive system cancers (pooled HR $=2.31,95 \%$ CI: 1.78-3.01), and there was no heterogeneity among the studies $\left(I^{2}=0.0 \%\right.$, $p=0.660$ ) (Figure 6).

\section{Association between TPX2 and clinicopathological characteristics of digestive system cancers}

A total of eight studies assessed the relationship between TPX2 expression and clinicopathological characteristics of digestive system cancers, including five about HCC, and three studies about ESCC, gastric cancer, and colorectal cancer, respectively. The pooled estimates showed that TPX2 expression was closely correlated with pathological grade (pooled HR $=3.438,95 \%$ CI: $2.040-5.794$ ) and TNM stage (pooled HR $=2.690,95 \%$ CI: $1.540-4.699$ ) in HCC, but was not related to most of the clinicopathological features, including age, gender, tumor size, hepatitis B surface antigen (HBsAg) status, alpha-fetoprotein (AFP), liver cirrhosis, tumor number, tumor encapsulation, and vascular invasion. 
A

Meta-analysis estimates, given named study is omitted

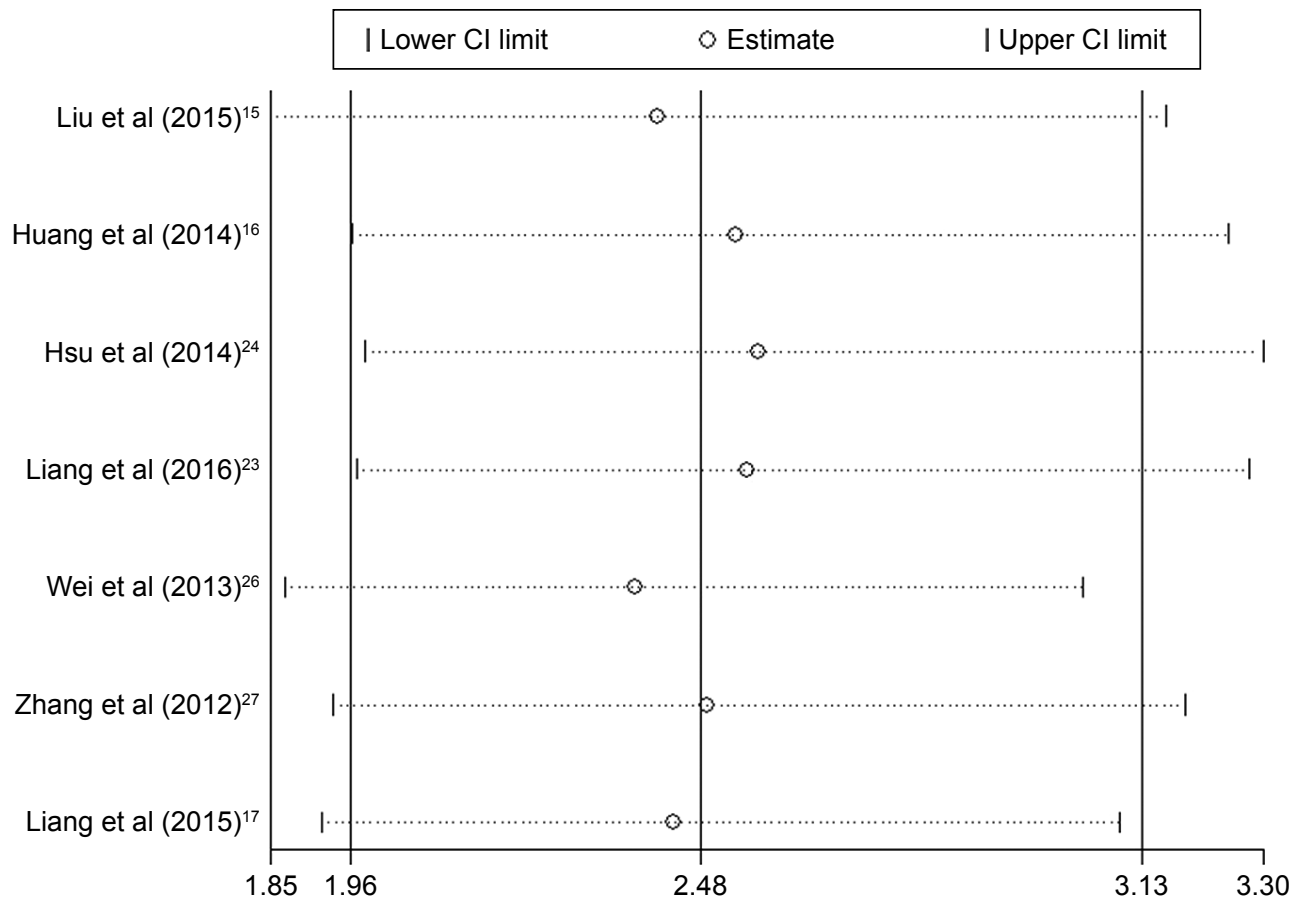

B

Meta-analysis estimates, given named study is omitted

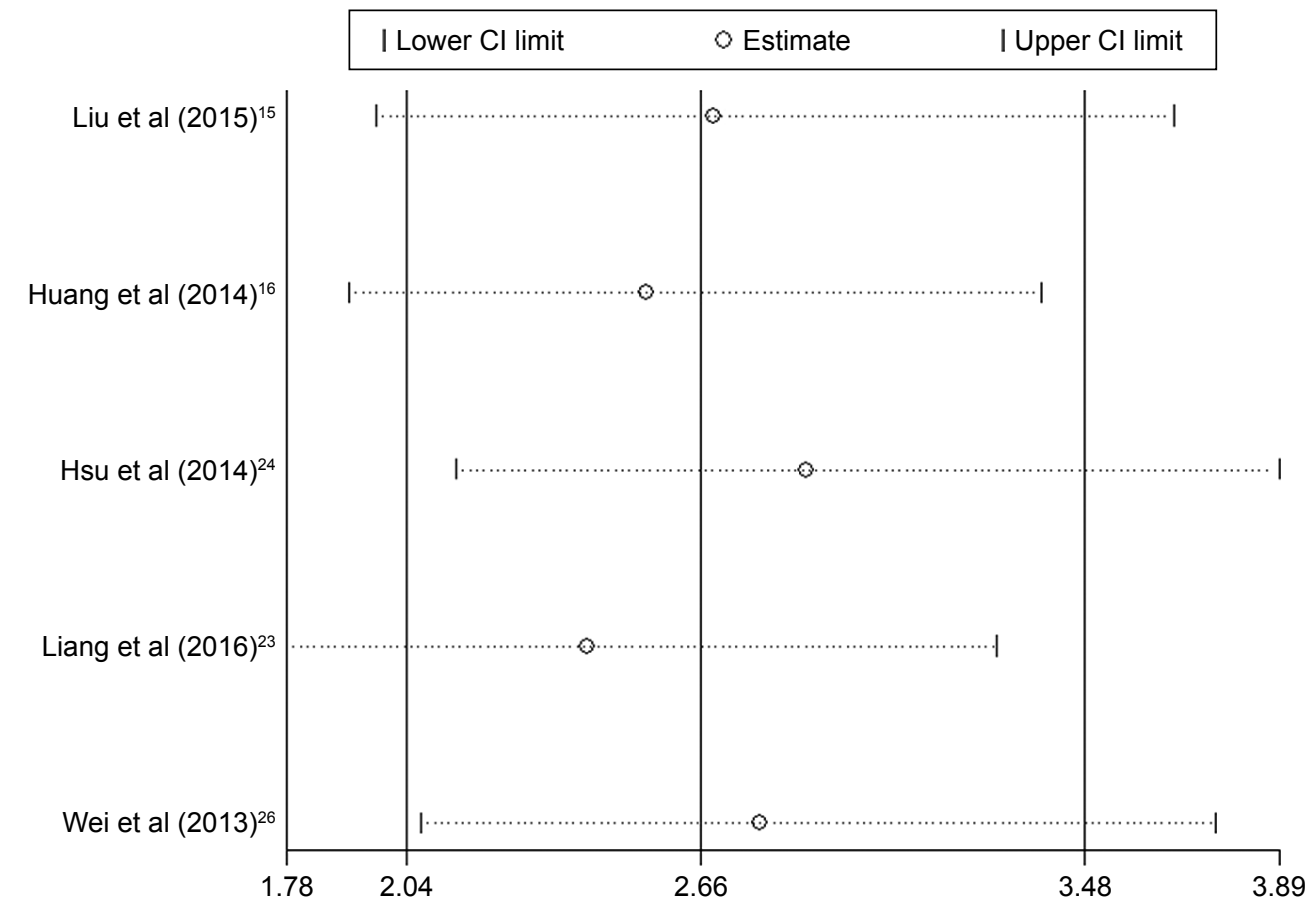

Figure 5 Sensitivity analysis of the effect of the individual study on the pooled HRs for the correlation between TPX2 and disease-free survival (A) and overall survival (B) in patients with digestive system cancer.

Abbreviations: TPX2, Xenopus kinesin-like protein 2; HR, hazard ratio; $\mathrm{Cl}$, confidence interval.

A significant relationship between TPX2 expression and lymph node metastasis (pooled HR $=2.341,95 \% \mathrm{CI}$ : 1.478-3.709), distant metastasis (pooled HR $=3.964,95 \%$ CI: 1.987-7.906), and TNM stage (pooled HR $=2.515$,
95\% CI: 1.332-4.746) was observed in three other cancers, including ESCC, gastric cancer (GC), and colorectal cancer. As shown in Table 3, there was no statistically significant publication bias across all the groups. 


\begin{tabular}{|c|c|c|}
\hline Study ID & $\operatorname{HR}(95 \% \mathrm{Cl})$ & Weight (\%) \\
\hline Liang et al $(2016)^{23}$ & $2.17(1.23-3.81)$ & 21.58 \\
\hline Hsu et al $(2014)^{24}$ & $1.80(1.04-3.13)$ & 22.59 \\
\hline Wei et al $(2013)^{26}$ & $2.20(1.20-3.90)$ & 19.86 \\
\hline Liu et al $(2015)^{15}$ & $2.58(1.52-4.38)$ & 24.65 \\
\hline Huang et al $(2014)^{16}$ & $3.70(1.70-8.10)$ & 11.32 \\
\hline Overall $\left(I^{2}=0.0 \%, p=0.660\right)$ & $2.31(1.78-3.01)$ & 100 \\
\hline
\end{tabular}

Figure 6 Meta-analysis of the independent role of TPX2 in overall survival of cancer patients. Note: Weights are from random-effects analysis.

Abbreviations: TPX2, Xenopus kinesin-like protein 2; HR, hazard ratio; $\mathrm{Cl}$, confidence interval.

\section{Publication bias}

Egger's regression plot and Begg's test were performed to assess the potential bias in the available literature. Egger's test revealed no evidence of potential publication bias for DFS $(p=0.232)$ and OS ( $p=0.785)$. In addition, Begg's test also indicated that there was no potential publication bias for DFS $(p=0.23)$ and OS (1.000) (Figure S3).

\section{Discussion}

This study explored the prognostic role of TPX2, an important regulatory molecule involved in spindle assembly and dynamics, in various types of digestive system malignancies. We used a comprehensive and detailed search strategy combined with predetermined inclusion and exclusion criteria, providing convincing evidence that the expression level of TPX2 is predictive of poor survival in digestive system cancers.

In total, 10 studies comprising 906 patients were included in the meta-analysis. Our pooled results showed that TPX2 might be utilized as an unfavorable and negative prognostic marker for digestive system cancer. We found that TPX2 overexpression is negatively correlated with OS, DFS, and RFS in patients with digestive system cancer. Moreover, the result of cumulative meta-analysis confirmed the stable trend of significant association between TPX2 and DFS and OS as time-accumulated. Stratified analyses were performed, and significant results pertaining to the relationship of TPX2 to a poor DFS were yielded in all subgroups on the basis of cancer type, sample size, quality of study, and laboratory detection method. Next, sensitivity analysis showed that no single study altered the pooled estimates significantly. Furthermore, the pooled results showed that TPX2 expression was an independent prognostic factor for DFS of patients with digestive system cancers. In addition, TPX2 expression was closely correlated with pathological grade and TNM stage in HCC. A significant relationship between TPX2 expression and lymph node metastasis, distant metastasis, and TNM stage was observed in ESCC, GC, and colorectal cancer. Besides, no statistically significant inter-study heterogeneity was found in our meta-analysis.

In addition to gastrointestinal cancer, TPX2 has also been reported to be highly expressed in other non-gastrointestinal cancers, such as bladder cancer, ${ }^{28}$ brain cancer, ${ }^{29}$ lung cancer, ${ }^{30,31}$ oral cancer, ${ }^{32}$ ovarian cancer, ${ }^{33}$ and salivary gland cancer. ${ }^{34}$ However, the mechanism by which TPX2 promotes cancer progression has not been fully elucidated so far. Martens-de Kemp et $\mathrm{al}^{35}$ identified 71 target genes by genome-wide siRNA screens, in which TPX2 was shown to be essential for tumor cell survival. Furthermore, in vivo and in vitro, silencing of TPX2 gene could reduce the tumorigenicity of cancer cells. ${ }^{26}$ Liu et al ${ }^{15}$ found that TPX2 could upregulate the expression of matrix metalloproteases2 (MMP2) by activation of the phosphatidylinositol 3-kinase (PI3K)/Akt signaling pathway in HCC. In addition to PI3K/Akt signaling pathway, TPX2 may partially activate the Ras/Raf/MEK/ ERK signaling pathway to promote tumor proliferation. ${ }^{26}$ 


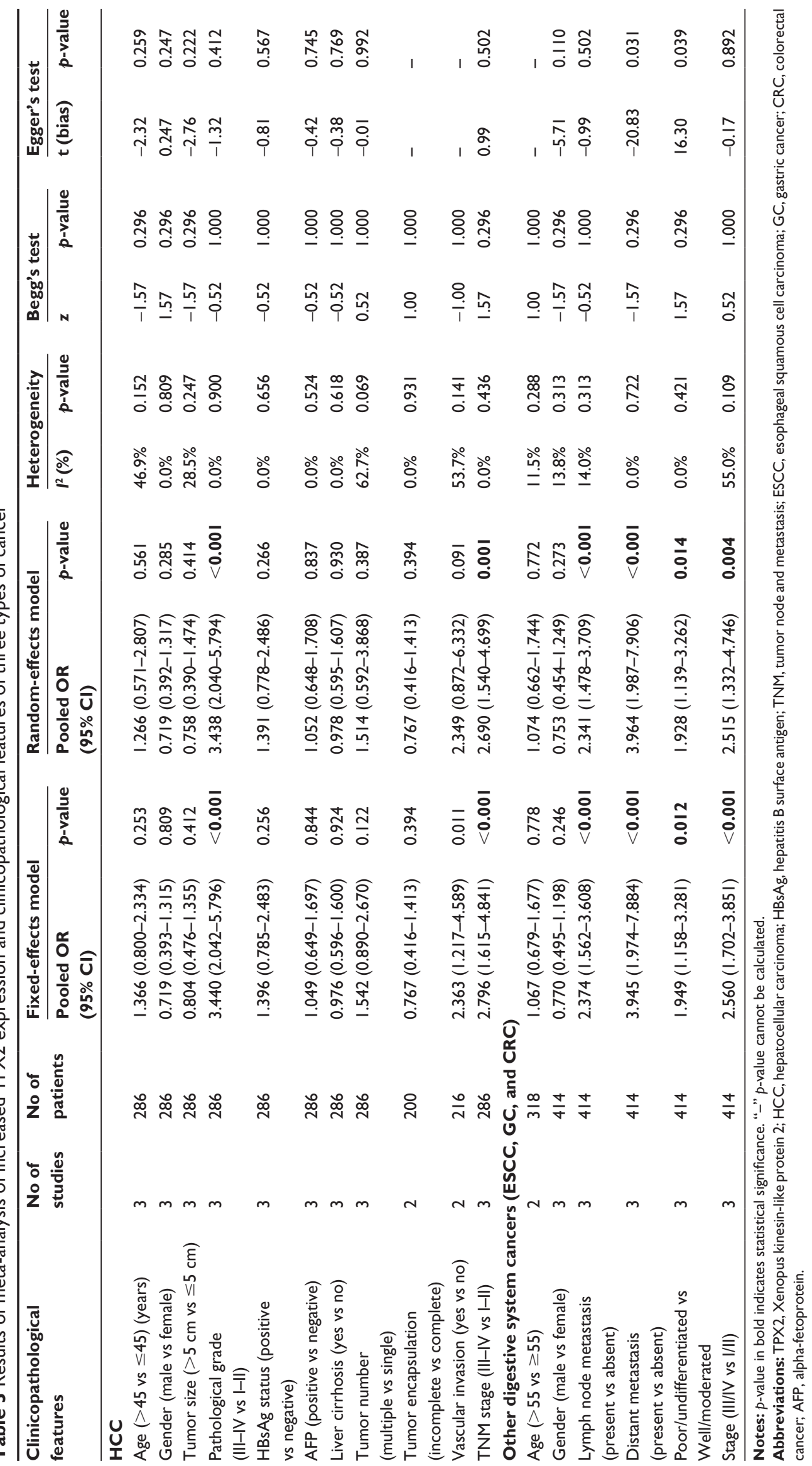


It has been known previously that the upregulation of TPX2 in cancer cells can promote epithelial-to-mesenchymal transition (EMT) by regulating the expression of EMT-related proteins. Depletion of TPX2 can lead to the upregulation of E-cadherin proteins that inhibit tumor metastasis and the downregulation of N-cadherin, $\beta$-catenin, Slug, MMP-9 and MMP-2 proteins that promote tumor metastasis. ${ }^{26}$ Moreover, TPX2 plays an important role in regulating cell cycle and proliferation. Wei et al found that silencing TPX2 through siRNA transfection significantly inhibited the cell cycle progression at $\mathrm{G} 1$ arrest. ${ }^{26}$ Collectively, previous studies indicate that TPX2 overexpression is associated with a tumor's proliferation, apoptosis, EMT, and invasiveness. However, further research is still needed.

The identification of prognostic factors is critical to distinguish high-risk patients who are good candidates for individualized treatment. Our findings suggested that TPX2 might potentially act as a clinical biomarker, and might also be a molecular target for cancer therapy. Recently, Kilchmann et $\mathrm{al}^{36}$ reported the discovery of a selective inhibitor of Aurora A. The inhibitor locks Aurora A in an inactive conformation and disrupts the function of TPX2. Chowdhury et $\mathrm{al}^{37}$ discovered that TPX2 might serve as a biomarker for identifying a subpopulation of patients who are sensitive to Aurora A-inhibitor treatment. Therefore, increasing studies will focus on TPX2 as a novel antitumor therapeutic approach in the future.

There were some limitations in our meta-analysis. First, all of the included patients were Asian, decreasing the applicability of the results across different ethnicities. Therefore, additional well-designed studies with patients of different ethnic backgrounds are highly needed to give more reliable results. Second, the cutoff value of TPX2 expression varied across different studies and a consensus value was rather difficult to reach. Third, in some studies, estimated HRs with corresponding 95\% CIs were calculated by Kaplan-Meier survival curves. Fourth, the number of studies enrolled in our analysis was relatively small. Finally, biological subtypes of a given tumor were not assessed because the distinction between different subtypes was not available for most of the studies.

\section{Conclusion}

In conclusion, this meta-analysis showed that TPX2 might be an independent prognostic factor for survival of patients with digestive system cancer. Furthermore, TPX2 expression might be associated with TNM stage and pathological grade in digestive system cancer. Additional well-designed studies with larger and more diverse populations are highly needed to validate our current data.

\section{Acknowledgments}

We thank Fengfang Xiao for critically reviewing the manuscript.

\section{Author contributions}

QW conceived the study, assessed the quality of the studies, and drafted the manuscript. GW and ZYL searched the literature, assessed the quality of the studies, performed the statistical analysis, and drafted the manuscript. CXL and XLH participated in the statistical analysis and drafted the manuscript. All authors read and approved the final manuscript.

\section{Disclosure}

The authors report no conflicts of interest in this work.

\section{References}

1. Poston GJ. Global cancer surgery: The Lancet Oncology review. Eur J Surg Oncol. 2015;41:1559-1561.

2. Bray F, Jemal A, Grey N, Ferlay J, Forman D. Global cancer transitions according to the Human Development Index (2008-2030): a populationbased study. Lancet Oncol. 2012;13:790-801.

3. Ferlay J, Shin HR, Bray F, Forman D, Mathers C, Parkin DM. Estimates of worldwide burden of cancer in 2008: GLOBOCAN 2008. Int J Cancer. 2010;127:2893-2917.

4. Torre LA, Bray F, Siegel RL, Lortet-Tieulent J, Jemal A. Global cancer statistics, 2012. CA Cancer J Clin. 2015;65:87-108.

5. Cortinovis D, Abbate M, Bidoli P, Capici S, Canova S. Targeted therapies and immunotherapy in non-small-cell lung cancer. Ecancermedicalscience. 2016;10:648.

6. Heidebrecht HJ, Buck F, Steinmann J, Sprenger R, Wacker HH, Parwaresch R. p100: a novel proliferation-associated nuclear protein specifically restricted to cell cycle phases S, G2, and M. Blood. 1997;90: 226-233.

7. Zhang Y, Heidebrecht H, Rott A, Schlegelberger B, Parwaresch R. Assignment of human proliferation associated p100 gene (C20orf1) to human chromosome band 20q11.2 by in situ hybridization. Cytogenet Cell Genet. 1999;84:182-183.

8. Wittmann T, Boleti H, Antony C, Karsenti E, Vernos I. Localization of the kinesin-like protein Xklp2 to spindle poles requires a leucine zipper, a microtubule-associated protein, and dynein. J Cell Biol. 1998; 143:673-685.

9. Perez de Castro I, Malumbres M. Mitotic Stress and chromosomal instability in cancer: the case for TPX2. Genes Cancer. 2012;3:721-730.

10. Wittmann T, Wilm M, Karsenti E, Vernos I. TPX2, a novel Xenopus MAP involved in spindle pole organization. $J$ Cell Biol. 2000;149: 1405-1418.

11. Kufer TA, Sillje HH, Korner R, Gruss OJ, Meraldi P, Nigg EA. Human TPX2 is required for targeting Aurora-A kinase to the spindle. J Cell Biol. 2002;158:617-623.

12. Gruss OJ, Wittmann M, Yokoyama H, et al. Chromosome-induced microtubule assembly mediated by TPX2 is required for spindle formation in HeLa cells. Nat Cell Biol. 2002;4:871-879.

13. Okamura H, Katabuchi H. Pathophysiological dynamics of human ovarian surface epithelial cells in epithelial ovarian carcinogenesis. Int Rev Cytol. 2005;242:1-254. 
14. Wang XX, Liu R, Jin SQ, Fan FY, Zhan QM. Overexpression of Aurora-A kinase promotes tumor cell proliferation and inhibits apoptosis in esophageal squamous cell carcinoma cell line. Cell Res. 2006; 16:356-366

15. Liu Q, Tu K, Zhang H, Zheng X, Yao Y, Liu Q. TPX2 as a novel prognostic biomarker for hepatocellular carcinoma. Hepatol Res. 2015; 45:906-918

16. Huang Y, Guo W, Kan H. TPX2 is a prognostic marker and contributes to growth and metastasis of human hepatocellular carcinoma. Int J Mol Sci. 2014;15:18148-18161.

17. Liang B, Jia C, Huang Y, et al. TPX2 level correlates with hepatocellular carcinoma cell proliferation, apoptosis, and EMT. Dig Dis Sci. 2015;60: $2360-2372$.

18. Liang B, Huang Y, He H, et al. [Expression of TPX2 in hepatocellular carcinoma and its clinical significance]. Zhonghua Yi Xue Za Zhi. 2015; 95:408-411. Chinese.

19. Moher D, Liberati A, Tetzlaff J, Altman DG, PRISMA Group. Preferred reporting items for systematic reviews and meta-analyses: the PRISMA statement. BMJ. 2009;339:b2535.

20. Tierney JF, Stewart LA, Ghersi D, Burdett S, Sydes MR. Practical methods for incorporating summary time-to-event data into meta-analysis. Trials. 2007;8:16.

21. Steels E, Paesmans M, Berghmans T, et al. Role of p53 as a prognostic factor for survival in lung cancer: a systematic review of the literature with a meta-analysis. Eur Respir J. 2001;18:705-719.

22. Satow R, Shitashige M, Kanai Y, et al. Combined functional genome survey of therapeutic targets for hepatocellular carcinoma. Clin Cancer Res. 2010;16:2518-2528.

23. Liang B, Zheng W, Fang L, et al. Overexpressed targeting protein for Xklp2 (TPX2) serves as a promising prognostic marker and therapeutic target for gastric cancer. Cancer Biol Ther. 2016;17:824-832.

24. Hsu PK, Chen HY, Yeh YC, et al. TPX2 expression is associated with cell proliferation and patient outcome in esophageal squamous cell carcinoma. J Gastroenterol. 2014;49:1231-1240.

25. Liu HC, Zhang Y, Wang XL, et al. Upregulation of the TPX2 gene is associated with enhanced tumor malignance of esophageal squamous cell carcinoma. Biomed Pharmacother. 2013;67:751-755.
26. Wei P, Zhang N, Xu Y, et al. TPX2 is a novel prognostic marker for the growth and metastasis of colon cancer. J Transl Med. 2013;11:313.

27. Zhang G, Schetter A, He P, et al. DPEP1 inhibits tumor cell invasiveness, enhances chemosensitivity and predicts clinical outcome in pancreatic ductal adenocarcinoma. PLoS One. 2012;7:e31507.

28. Yan L, Li S, Xu C, et al. Target protein for Xklp2 (TPX2), a microtubulerelated protein, contributes to malignant phenotype in bladder carcinoma. Tumour Biol. 2013;34:4089-4100.

29. Li B, Qi XQ, Chen X, et al. Expression of targeting protein for Xenopus kinesin-like protein 2 is associated with progression of human malignant astrocytoma. Brain Res. 2010;1352:200-207.

30. Lin DM, Ma Y, Xiao T, et al. [TPX2 expression and its significance in squamous cell carcinoma of lung]. Zhonghua Bing Li Xue Za Zhi. 2006; 35:540-544. Chinese.

31. Ma Y, Lin D, Sun W, et al. Expression of targeting protein for xklp2 associated with both malignant transformation of respiratory epithelium and progression of squamous cell lung cancer. Clin Cancer Res. 2006; 12:1121-1127.

32. Shigeishi H, Fujimoto S, Hiraoka M, et al. Overexpression of the receptor for hyaluronan-mediated motility, correlates with expression of microtubule-associated protein in human oral squamous cell carcinomas. Int J Oncol. 2009;34:1565-1571.

33. Caceres-Gorriti KY, Carmona E, Barres V, et al. RAN nucleo-cytoplasmic transport and mitotic spindle assembly partners XPO7 and TPX2 are new prognostic biomarkers in serous epithelial ovarian cancer. PLoS One. 2014;9:e91000.

34. Shigeishi H, Ohta K, Hiraoka M, et al. Expression of TPX2 in salivary gland carcinomas. Oncol Rep. 2009;21:341-344.

35. Martens-de Kemp SR, Nagel R, Stigter-van Walsum M, et al. Functional genetic screens identify genes essential for tumor cell survival in head and neck and lung cancer. Clin Cancer Res. 2013;19:1994-2003.

36. Kilchmann F, Marcaida MJ, Kotak S, et al. Discovery of a selective Aurora A kinase inhibitor by virtual screening. J Med Chem. 2016;59: 7188-7211.

37. Chowdhury A, Chowdhury S, Tsai MY. A novel Aurora kinase A inhibitor MK-8745 predicts TPX2 as a therapeutic biomarker in nonHodgkin lymphoma cell lines. Leuk Lymphoma. 2012;53:462-471. 


\section{Supplementary materials}

Table SI PRISMA 2009 checklist

\begin{tabular}{|c|c|c|c|}
\hline Section/topic & \# & Checklist item & $\begin{array}{l}\text { Reported } \\
\text { on page \# }\end{array}$ \\
\hline \multicolumn{4}{|l|}{ Title } \\
\hline Title & I & Identify the report as a systematic review, meta-analysis, or both. & I \\
\hline \multicolumn{4}{|l|}{ Abstract } \\
\hline $\begin{array}{l}\text { Structured } \\
\text { summary }\end{array}$ & 2 & $\begin{array}{l}\text { Provide a structured summary including, as applicable: background; objectives; data sources; study } \\
\text { eligibility criteria, participants, and interventions; study appraisal and synthesis methods; results; } \\
\text { limitations; conclusions and implications of key findings; systematic review registration number. }\end{array}$ & 2 \\
\hline \multicolumn{4}{|l|}{ Introduction } \\
\hline Rationale & 3 & Describe the rationale for the review in the context of what is already known. & $3 \sim 4$ \\
\hline Objectives & 4 & $\begin{array}{l}\text { Provide an explicit statement of questions being addressed with reference to participants, interventions, } \\
\text { comparisons, outcomes, and study design (PICOS). }\end{array}$ & $3 \sim 4$ \\
\hline \multicolumn{4}{|l|}{ Methods } \\
\hline $\begin{array}{l}\text { Protocol and } \\
\text { registration }\end{array}$ & 5 & $\begin{array}{l}\text { Indicate if a review protocol exists, if and where it can be accessed (eg, web address), and, if available, } \\
\text { provide registration information including registration number. }\end{array}$ & NA \\
\hline Eligibility criteria & 6 & $\begin{array}{l}\text { Specify study characteristics (eg, PICOS, length of follow-up) and report characteristics (eg, years } \\
\text { considered, language, publication status) used as criteria for eligibility, giving rationale. }\end{array}$ & $4-5$ \\
\hline $\begin{array}{l}\text { Information } \\
\text { sources }\end{array}$ & 7 & $\begin{array}{l}\text { Describe all information sources (eg, databases with dates of coverage, contact with study authors to } \\
\text { identify additional studies) in the search and date last searched. }\end{array}$ & 4 \\
\hline Search & 8 & $\begin{array}{l}\text { Present full electronic search strategy for at least one database, including any limits used, such that it } \\
\text { could be repeated. }\end{array}$ & 4 \\
\hline Study selection & 9 & $\begin{array}{l}\text { State the process for selecting studies (ie, screening, eligibility, included in systematic review, and, if } \\
\text { applicable, included in the meta-analysis). }\end{array}$ & 4 \\
\hline $\begin{array}{l}\text { Data collection } \\
\text { process }\end{array}$ & 10 & $\begin{array}{l}\text { Describe the method of data extraction from reports (eg, piloted forms, independently, in duplicate) and } \\
\text { any processes for obtaining and confirming data from investigators. }\end{array}$ & 5 \\
\hline Data items & II & $\begin{array}{l}\text { List and define all variables for which data were sought (eg, PICOS, funding sources) and any assumptions } \\
\text { and simplifications made. }\end{array}$ & 5 \\
\hline $\begin{array}{l}\text { Risk of bias in } \\
\text { individual studies }\end{array}$ & 12 & $\begin{array}{l}\text { Describe the methods used for assessing the risk of bias of individual studies (including specification of } \\
\text { whether this was done at the study or outcome level), and how this information is to be used in any data } \\
\text { synthesis. }\end{array}$ & 6 \\
\hline $\begin{array}{l}\text { Summary } \\
\text { measures }\end{array}$ & 13 & State the principal summary measures (eg, risk ratio, difference in means). & 7 \\
\hline $\begin{array}{l}\text { Synthesis of } \\
\text { results }\end{array}$ & 14 & $\begin{array}{l}\text { Describe the methods of handling data and combining results of studies, if done, including measures of } \\
\text { consistency }\left(\mathrm{eg}, P^{2}\right) \text { for each meta-analysis. }\end{array}$ & 6 \\
\hline
\end{tabular}

Abbreviations: PRISMA, Preferred Reporting Items for Systematic Reviews and Meta-Analyses; NA, not available.

Table S2 Quality assessment of the included studies based on the quality scale for biological prognostic factors

\begin{tabular}{|c|c|c|c|c|c|}
\hline Study & $\begin{array}{l}\text { Scientific } \\
\text { design }\end{array}$ & $\begin{array}{l}\text { Laboratory } \\
\text { methodology }\end{array}$ & Generalizability & $\begin{array}{l}\text { Results } \\
\text { analysis }\end{array}$ & $\begin{array}{l}\text { Global score } \\
\text { (\%) }\end{array}$ \\
\hline Liu et al (2015)' & 9 & 11 & 10 & 7 & 93 \\
\hline Huang et al $(2014)^{2}$ & 8 & 8 & 10 & 6 & 80 \\
\hline Liang et al $(2015)^{3}$ & 8 & 11 & 10 & 7 & 90 \\
\hline Satow et al $(2010)^{4}$ & 8 & 10 & 9 & 2 & 73 \\
\hline Liang et al $(2015)^{5}$ & 9 & 11 & 10 & 4 & 85 \\
\hline Liang et al $(2016)^{6}$ & 9 & 10 & 9 & 6 & 85 \\
\hline Hsu et al $(2014)^{7}$ & 8 & 10 & 10 & 4 & 80 \\
\hline Liu et al $(2013)^{8}$ & 8 & 9 & 8 & 2 & 68 \\
\hline Wei et al $(2013)^{9}$ & 9 & 10 & 9 & 4 & 80 \\
\hline Zhang et al $(2012)^{10}$ & 8 & 9 & 8 & 4 & 73 \\
\hline
\end{tabular}




\begin{tabular}{|c|c|}
\hline Year & $\mathrm{HR}(95 \% \mathrm{Cl})$ \\
\hline 2015 & $2.67(1.68-4.24)$ \\
\hline 2014 & $2.49(1.72-3.59)$ \\
\hline 2014 & $2.37(1.74-3.22)$ \\
\hline 2016 & $2.32(1.77-3.04)$ \\
\hline 2013 & $2.44(1.89-3.15)$ \\
\hline 2012 & $2.44(1.92-3.09)$ \\
\hline 2015 & $2.48(1.96-3.13)$ \\
\hline
\end{tabular}

Figure SI Cumulative meta-analysis of the correlation between TPX2 overexpression and DFS according to the time of publication. Abbreviations: TPX2, Xenopus kinesin-like protein 2; HR, hazard ratio; $\mathrm{Cl}$, confidence interval.

\begin{tabular}{|c|c|}
\hline Year & HR (95\% CI) \\
\hline 2015 & $2.58(1.52-4.38)$ \\
\hline 2014 & $2.89(1.87-4.48)$ \\
\hline 2014 & $2.50(1.76-3.57)$ \\
\hline 2016 & $2.79(2.07-3.75)$ \\
\hline 2013 & $2.66(2.04-3.48)$ \\
\hline
\end{tabular}

Figure S2 Cumulative meta-analysis of the correlation between TPX2 overexpression and OS according to the time of publication. Abbreviations: TPX2, Xenopus kinesin-like protein 2; OS, overall survival; HR, hazard ratio; $\mathrm{Cl}$, confidence interval.

A

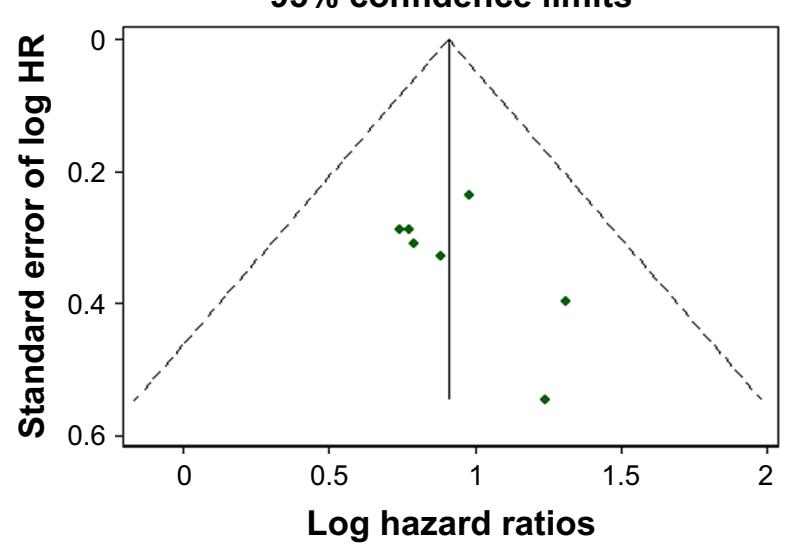

Bunnel plot with pseudo
$95 \%$ confidence limits

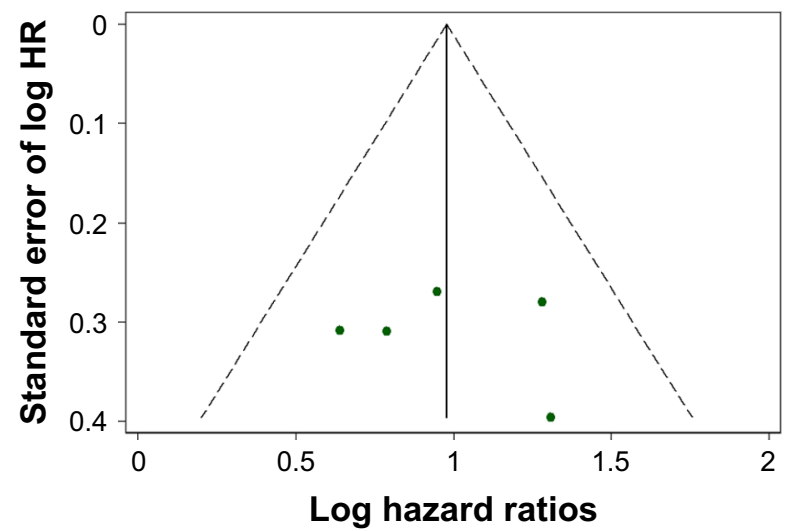

Figure S3 Funnel plot for publication bias of studies for DFS (A) and OS (B).

Abbreviations: DFS, disease-free survival; OS, overall survival; $H R$, hazard ratio. 


\section{References}

1. Liu Q, Tu K, Zhang H, Zheng X, Yao Y, Liu Q. TPX2 as a novel prognostic biomarker for hepatocellular carcinoma. Hepatol Res. 2015;45: 906-918.

2. Huang Y, Guo W, Kan H. TPX2 is a prognostic marker and contributes to growth and metastasis of human hepatocellular carcinoma. Int J Mol Sci. 2014;15:18148-18161.

3. Liang B, Huang Y, He H, et al. [Expression of TPX2 in hepatocellular carcinoma and its clinical significance]. Zhonghua Yi Xue Za Zhi. 2015; 95:408-411. Chinese.

4. Satow R, Shitashige M, Kanai Y, et al. Combined functional genome survey of therapeutic targets for hepatocellular carcinoma. Clin Cancer Res. 2010;16:2518-2528.

5. Liang B, Jia C, Huang Y, et al. TPX2 level correlates with hepatocellular carcinoma cell proliferation, apoptosis, and EMT. Dig Dis Sci. 2015;60: 2360-2372.
6. Liang B, Zheng W, Fang L, et al. Overexpressed targeting protein for Xklp2 (TPX2) serves as a promising prognostic marker and therapeutic target for gastric cancer. Cancer Biol Ther. 2016;17:824-832.

7. Hsu PK, Chen HY, Yeh YC, et al. TPX2 expression is associated with cell proliferation and patient outcome in esophageal squamous cell carcinoma. J Gastroenterol. 2014;49:1231-1240.

8. Liu HC, Zhang Y, Wang XL, et al. Upregulation of the TPX2 gene is associated with enhanced tumor malignance of esophageal squamous cell carcinoma. Biomed Pharmacother. 2013;67:751-755.

9. Wei P, Zhang N, Xu Y, et al. TPX2 is a novel prognostic marker for the growth and metastasis of colon cancer. J Transl Med. 2013;11:313.

10. Zhang G, Schetter A, He P, et al. DPEP1 inhibits tumor cell invasiveness, enhances chemosensitivity and predicts clinical outcome in pancreatic ductal adenocarcinoma. PLoS One. 2012;7:e31507.

\section{Publish your work in this journal}

OncoTargets and Therapy is an international, peer-reviewed, open access journal focusing on the pathological basis of all cancers, potential targets for therapy and treatment protocols employed to improve the management of cancer patients. The journal also focuses on the impact of management programs and new therapeutic agents and protocols on

\section{Dovepress}

patient perspectives such as quality of life, adherence and satisfaction. The manuscript management system is completely online and includes a very quick and fair peer-review system, which is all easy to use. Visit http://www.dovepress.com/testimonials.php to read real quotes from published authors.

Submit your manuscript here: http://www.dovepress.com/oncotargets-and-therapy-journal 